\section{Kidney \\ Blood Pressure Research}

\title{
Pancreatic Kininogenase Ameliorates Renal Fibrosis in Streptozotocin Induced-Diabetic Nephropathy Rat
}

\author{
Dan Zhu ${ }^{\mathrm{a}} \quad$ Linlin Zhang ${ }^{\mathrm{a}} \quad$ Lijuan Cheng $^{\mathrm{a}} \quad$ Liansheng Ren $^{\mathrm{a}} \quad$ Jie Tang ${ }^{\mathrm{a}}$ \\ Dianjun Sun ${ }^{b}$
}

aDepartment of Nephrology, The First Affiliated Hospital of Harbin Medical University, Heilongjiang; ${ }^{b}$ Center for Endemic Disease Control, Chinese Center for Disease Control and Prevention, Harbin Medical University; Key Lab of Etiology and Epidemiology, Education Bureau of Hei Long Jiang Province \& Ministry of Health (23618104), Harbin, China

\section{Key Words}

Pancreatic Kininogenase • Renal fibrosis • Transforming growth factor- $\beta 1$ - Antizyme inhibitor 1 - MiR-433

\begin{abstract}
Background/Aims: We aimed to evaluate whether pancreatic kininogenase (PKase) can relieve renal fibrosis and investigate its mechanisms in diabetic nephropathy (DN) rats Methods: We established streptozotocin (STZ) induced-DN rats. After treatment with PKase for 4 weeks, urinary weight, urinary protein content and blood glucose concentration were detected, and then renal histopathological changes were examined using Hematoxylin and Eosin (H\&E) and Masson's thrchrome staining. In addition, the expressions of miR-433, transforming growth factor- $\beta 1$ (TGF- $\beta 1$ ) and antizyme inhibitor 1 (Azin1) were detected by qRT-PCR and/or western blotting. Results: PKase reduced urinary weight, urinary protein contents and blood glucose concentrations. PKase treated DN rats exhibited less renal fibrosis than untreated DN rats $(P$ $<0.05)$. Furthermore, the expression levels of TGF- $\beta$ and miR-433 were reduced $(P<0.05)$, while Azin1 expression was increased in renal tissues of PKase treated DN rats compared with untreated DN rats $(P<0.05)$. Conclusions: PKase might not only inhibit the development of DN by reducing urinary weight, urinary protein content and blood glucose concentration in DN rats, but also relieve renal fibrosis in DN rats through inhibiting the expression of TGF- $\beta 1$, and miR433 and Azin1 might involve in this process.
\end{abstract}




\section{Kidney Blood Pressure Research}

Kidney Blood Press Res 2016;41:9-17

DOI: $10.1159 / 000368542$

Published online: January 08, 2016

(C) 2016 The Author(s). Published by S. Karger AG, Base

www.karger.com/kbr

Zhu/Zhang/Cheng/Ren/Tang: Sun2Effect of PKase on STZ induced-DN rats

\section{Introduction}

Diabetic nephropathy (DN), a common microvascular complication in patients with diabetes, is characterized by proteinuria, decreased glomerular filtration, renal hypertrophy and tubulointerstitial fibrosis $[1,2]$. Although therapeutic approaches to glycemic control and renoprotective drugs have been performed [3], DN is still considered as the major cause of end-stage renal disease that may result in severe mortality [4]. Therefore, it is essential to study the molecular mechanism of DN and search for effective treatment methods.

A variety of the pathogenesis of $\mathrm{DN}$, including genetic factors, oxidative stress, hemodynamic factors, inflammatory factors and growth factors, have been reported [5]. Pancreatic kininogenase (PKase), which extracted from pig pancreas tissue, has been reported as one of the main drugs for the treatment of DN through promoting the release of kinins [6, 7]. The kallikrein-kinin system (KKS) comprises a series of enzymes and peptides including kallikreins, kininogens, and kininases that can regulate the synthesis and release of kinins [8]. Previous study has shown that kinins can enhance the hemangiectasis, improve minicirculation, and regulate blood pressure, as well as prevent the thrombosis and the thickening of basement membrane, which suggest that KKS is associated with the progression of DN [9]. However, the effect and precise mechanisms of PKase on renal fibrosis in the development of DN remain unclear.

It is well known that transforming growth factor- $\beta 1$ (TGF- $\beta 1$ ) has a pro-fibrogenic effect through regulating the production of extracellular matrix (ECM) [10-12]. Overexpressed TGF- $\beta 1$ has been proved in human and experimental DN [13], and inhibiting the expression of TGF- $\beta 1$ can ameliorate several pathological symptoms of DN $[14,15]$, indicating that the reduction of ECM deposition in the kidney may be an available treatment for DN. Recent study has shown that overexpression of miR-433 can promote renal fibrosis by regulating the TGF- $\beta$-antizyme inhibitor 1 (Azin1) pathway [16]. Therefore, in the present study, streptozotocin (STZ) induced-DN rats were treated with PKase, and then the pathologic changes as well as the expressions of miR-433, TGF- $\beta 1$ and Azin1 were examined. We aimed to evaluate whether PKase could relieve renal fibrosis in STZ-induced DN rats and further investigate its mechanisms.

\section{Materials and Methods}

\section{Animal model and grouping}

A total of 18 Sprague-Dawley (SD) rats (male, about $90 \mathrm{~g}$ ) were provided by the SLRC Laboratory Animal Co., Ltd (Shanghai, China), and then acclimatized under appropriate condition for a week before the trial. Approval from the Animal Ethics Committee of the Animal Laboratory Center of the First Affiliated Hospital of Harbin Medical University was obtained prior to using the animals for research. Eighteen rats were randomly and equally divided into three groups: control group; DN group; and PKase group. All the rats were fasted for $12 \mathrm{~h}$ before experiments. The rats in DN and PKase groups were treated with 60 $\mathrm{mg} / \mathrm{kg}$ STZ (Sigma, St. Louis, MO, USA) dissolved in physiological saline by intraperitoneal injection [17]. Meanwhile, the rats in control group were treated with $0.9 \%$ sodium chloride solution in an equal volume. After treatment for $72 \mathrm{~h}$, blood samples were collected for the detection of blood glucose content using blood glucose monitor (Omnitest plus, Germany). Additionally, single rat was placed in a metabolic cage to collect a 24-h urine. Then, urinary weight of each rat was measured, and urinary protein content of each rat was detected using urinary protein detection kits (Nanjing Jiancheng Bioengineering Institute, Jiangsu, China). DN rats were confirmed by postprandial blood glucose concentration between $16.0 \mathrm{mM}$ and $30 \mathrm{mM}$ [18].

Drug administration and samples collection

Once the successful DN model had been established, the rats in PKase group were treated with PKase (7.2 U/kg·d, Shanghai Future Industrial Co., Ltd, China) dissolved in physiological saline once daily for 4 


\section{Kidney \\ Blood Pressure Research}

Kidney Blood Press Res 2016;41:9-17

\begin{tabular}{l|l}
\hline DOI: 10.1159/000368542 & (C) 2016 The Author(s). Published by S. Karger AG, Base
\end{tabular}

Published online: January 08, 2016

www.karger.com $/ \mathrm{kbr}$ weeks. Simultaneously, the rats in control and DN groups were treated with the same amount of physiological saline. After 4 weeks, blood samples were collected to detect blood glucose content, and a 24-h urine was obtained to measure urinary weight as well as urinary protein content. Then, all the rats were sacrificed and renal tissues were collected. Some renal tissues were fixed in $4 \%$ paraformaldehyde for histological analysis, and others were rapidly frozen and then stored at $-80^{\circ} \mathrm{C}$ for the quantitative real-time PCR (qRT-PCR) and western blotting analysis.
Table 1. Primer sequences for specific genes

\begin{tabular}{ll}
\hline Gene & Primer sequences $\left(5^{\prime}-3^{\prime}\right)$ \\
\hline \multirow{2}{*}{ TGF- $\beta 1$} & Forward: GAGGCGGTGCTCGCTTTGTA \\
& Reverse: TGTTGCGGTCCACCATTAGC \\
Azin1 & Forward: GCACAGTCAGTGGCAGAACG \\
& Reverse: CAGTTCCAAGAGCTGCCAAG \\
\multirow{2}{*}{-actin } & Forward: CCCATCTATGAGGGTTACGC \\
& Reverse: TTTAATGTCACGCACGATTTC \\
\hline
\end{tabular}

TGF- $\beta 1$, transforming growth factor- $\beta 1$; Azin1, antizyme inhibitor 1

\section{qRT-PCR}

The mRNA levels of TGF- $\beta 1$ and Azin1 were detected by qRT-PCR according to previous study [19]. Briefly, the total RNA was extracted using $800 \mu \mathrm{L}$ Trizol reagent (Invitrogen, USA) and high-quality RNA was reversely transcribed into complementary DNA with a Reverse Transcription Kit (TaKaRa Bio., China). Primers for TGF- $\beta 1$, Azin1 and $\beta$-actin are shown in Table 1. PCR amplification was performed with SYBR $®$ Premix Ex Taq ${ }^{\mathrm{TM}}$ (TaKaRa). The PCR program was: $95^{\circ} \mathrm{C}$ for $3 \mathrm{~min}, 40$ cycles of $95^{\circ} \mathrm{C}$ for $10 \mathrm{~s}$ and $60^{\circ} \mathrm{C}$ for $30 \mathrm{~s}$, using the ABI Stepone plus Real-time PCR system (Applied Biosystems, Foster City, CA, USA). In addition, the detection of miR-433 level was performed by Shanghai Qiyin biotechnology Co., Ltd (China). Relative quantification was calculated using the comparative threshold $(C \mathrm{t})$ cycle method $\left(2^{-\Delta \Delta} C \mathrm{t}\right)$.

\section{Western-blotting}

The expressions of TGF- $\beta 1$ and Azin1 proteins were detected by western-blotting as previously described [19]. In brief, the tissues were milled and then placed on ice for 30 min in RIPA lysis buffer (Beyotime Institute of Biotechnology, China) containing $1 \mathrm{mM}$ Phenylmethanesulfonyl fluoride (Shanghai Sangon Biotech Co., Ltd, China). Supernatant were acquired after centrifugation for 20 min at 12,000 rpm at $4^{\circ} \mathrm{C}$. Subsequently, protein concentration was measured by the BCA Protein Quantitative Assay (Shanghai Sangon Biotech Co., Ltd, China). Protein samples were separated on 12\% SDS-PAGE gel, and then transferred onto PVDF membranes. The membranes were blocked in 5\% defatted milk for $1 \mathrm{~h}$ at room temperature, and then incubated overnight at $4^{\circ} \mathrm{C}$ with rabbit anti-rat glyceraldehyde-3-phosphate dehydrogenase (GAPDH) monoclonal antibody (1:1000, Jackson Labs, Bar Harbor, ME, USA), rabbit anti-ratAzin1 monoclonal antibody (1:500, Proteintech, Chicago, IL, USA), and rabbit anti-rat TGF- $\beta 1$ polyclonal antibody (1:500, Proteintech), respectively. After washed for three times with phosphate buffer solution, the membranes were incubated with goat anti-rabbit IgG (H+L)-HRP $\left(1: 5000\right.$, Jackson) for $2 \mathrm{~h}$ at $25^{\circ} \mathrm{C}$, respectively. Ultimately, the proteins were detected with Enhanced chemiluminescence (ECL, Millipore, USA) and analyzed by densitometry using the Image-J imaging analysis software (NIH, Bethesda, MD).

\section{Hematoxylin and Eosin (H\&E) and Masson's thrchrome staining}

The tissues were fixed in $4 \%$ paraformaldehyde for $24 \mathrm{~h}$, and then embedded into paraffin blocks. Next, sections were baked for $4 \mathrm{~h}$ for deparaffinization at $65^{\circ} \mathrm{C}$ and dehydrated with gradient ethanol. Subsequently, the sections were stained using hematoxylin for 5-10 min. For HE staining, after differentiated in $1 \%$ hydrochloric acid alcohol for $2 \mathrm{~s}$, the sections were incubated in ammonia water for $2 \mathrm{~min}$, and stained with eosin for $1 \mathrm{~min}$. For Masson's thrchrome staining, sections were incubated in Masson-ponceau for 5-10 min, rinsed with $2 \%$ acetic acid solution, differentiated in 1\% phosphomolybdic acid for 3-5 min, and then stained with aniline blue for $5 \mathrm{~min}$. Ultimately, the sections were dehydrated, cleared, and mounted with neutral resin. Light microscopy (Olympus, Japan) was used to observe the sections and the fibrosis staining areas were analyzed by densitometry using the Image-J imaging analysis software (NIH, Bethesda, MD) and the percentages of fibrosis positive area were calculated. 


\section{Kidney Blood Pressure Research}

Zhu/Zhang/Cheng/Ren/Tang: Sun2Effect of PKase on STZ induced-DN rats

Statistical analysis

Statistical

analysis was used to analyze data by SPSS 19.0 statistical analysis software (SPSS Inc., Chicago, IL, USA). Continuous variables were analyzed using the normality test. If in accord with normal distribution, data were expressed as the mean \pm S.D and analyzed by One-way ANOVA. Conversely, if data did not coincided with normal distribution, nonparametric test was used to assess the significance of difference. A value of $P$ less than 0.05 was considered significant.
Table 2. Urinary weight in control, diabetic nephropathy (DN) and pancreatic kininogenase (PKase) groups

\begin{tabular}{lccc}
\hline Times & Control group $(\mathrm{g})$ & DN group $(\mathrm{g})$ & PKase group $(\mathrm{g})$ \\
\hline 0 week & $18.17 \pm 4.48$ & $103.33 \pm 4.71^{*}$ & $105.00 \pm 16.50^{*}$ \\
1 week & $19.50 \pm 2.74$ & $126.67 \pm 10.95^{*}$ & $120.00 \pm 18.26^{*}$ \\
2 weeks & $18.5 \pm 2.00$ & $101.67 \pm 12.78^{*}$ & $95.00 \pm 9.13^{*}$ \\
3 weeks & $21.00 \pm 4.75$ & $111.67 \pm 12.78^{*}$ & $90.00 \pm 3.65^{* \#}$ \\
4 weeks & $25.83 \pm 2.74$ & $115.00 \pm 12.78^{*}$ & $76.67 \pm 3.65^{* \#}$ \\
\hline
\end{tabular}

${ }^{*} P<0.05$ versus control group, ${ }^{\#} P<0.05$ versus DN group

Table 3. Urinary protein in control, diabetic nephropathy (DN) and pancreatic kininogenase (PKase) groups

\begin{tabular}{lccc}
\hline Times & Control group (mg) & DN group (mg) & PKase group (mg) \\
\hline 0 week & $2.08 \pm 0.40$ & $26.30 \pm 1.98^{*}$ & $26.45 \pm 1.96^{*}$ \\
1 week & $2.45 \pm 0.16$ & $26.07 \pm 1.35^{*}$ & $25.48 \pm 1.59^{*}$ \\
2 weeks & $2.38 \pm 0.27$ & $26.52 \pm 2.25^{*}$ & $23.90 \pm 0.66^{* \#}$ \\
3 weeks & $3.08 \pm 0.68$ & $29.63 \pm 1.53^{*}$ & $23.61 \pm 0.13^{* \#}$ \\
4 weeks & $2.63 \pm 0.15$ & $32.45 \pm 1.55^{*}$ & $18.38 \pm 1.70^{* \#}$ \\
\hline
\end{tabular}

${ }^{*} P<0.05$ versus control group, $\# P<0.05$ versus DN group

Table 4. Blood glucose in control, diabetic nephropathy (DN) and pancreatic kininogenase (PKase) groups

\begin{tabular}{lccc}
\hline Times & Control group (mM) & DN group $(\mathrm{mM})$ & PKase group $(\mathrm{mM})$ \\
\hline 0 week & $8.72 \pm 1.36$ & $26.50 \pm 1.94^{*}$ & $26.68 \pm 1.46^{*}$ \\
1 week & $8.32 \pm 0.79$ & $26.69 \pm 2.12^{*}$ & $24.97 \pm 1.18^{* \#}$ \\
2 weeks & $9.68 \pm 1.82$ & $27.28 \pm 2.27^{*}$ & $24.35 \pm 1.56^{* \#}$ \\
3 weeks & $9.63 \pm 2.04$ & $25.93 \pm 1.99^{*}$ & $20.05 \pm 3.20^{* \#}$ \\
4 weeks & $9.08 \pm 1.47$ & $27.85 \pm 1.67^{*}$ & $18.93 \pm 2.67^{* \#}$ \\
\hline${ }^{*} P<0.05$ versus control group, ${ }^{*} P<0.05$ versus DN group \\
\hline
\end{tabular}

\section{Results}

Effect of PKase on urinary weight, urinary protein and blood glucose in DN rats

Compared with the control group, urinary weight and urinary protein contents remarkably increased in the DN and PKase groups before treatment $(P<0.05$, Table 2, 3). After treatment with PKase for 3 and 4 weeks, urinary weight and urinary protein contents in the PKase group were lower than that in the DN group $(P<0.05$, Table 2,3$)$. In addition, we found that blood glucose concentrations were higher in the DN and PKase groups than that in the control group, and blood glucose concentrations of DN and PKase groups were more than $16.0 \mathrm{mM}$ before treatment $(P<0.05$, Table 4$)$, suggesting that STZ-induced DN rats were successfully established. Also, after treatment with PKase for 1, 2, 3 and 4 weeks, blood glucose concentrations in the PKase group remarkably reduced compared with the DN group $(P<0.05$, Table 4$)$.

\section{Effect of PKase on renal fibrosis in DN rats}

HE staining showed that no pathological changes were observed in glomerulus and renal tubular in the renal tissues of control group, while renal tissues in the DN group exhibited mesenteria matrix hyperplasia and glomerular basement thickening (Fig. 1). After treatment 


\section{Kidney \\ Blood Pressure \\ Research}

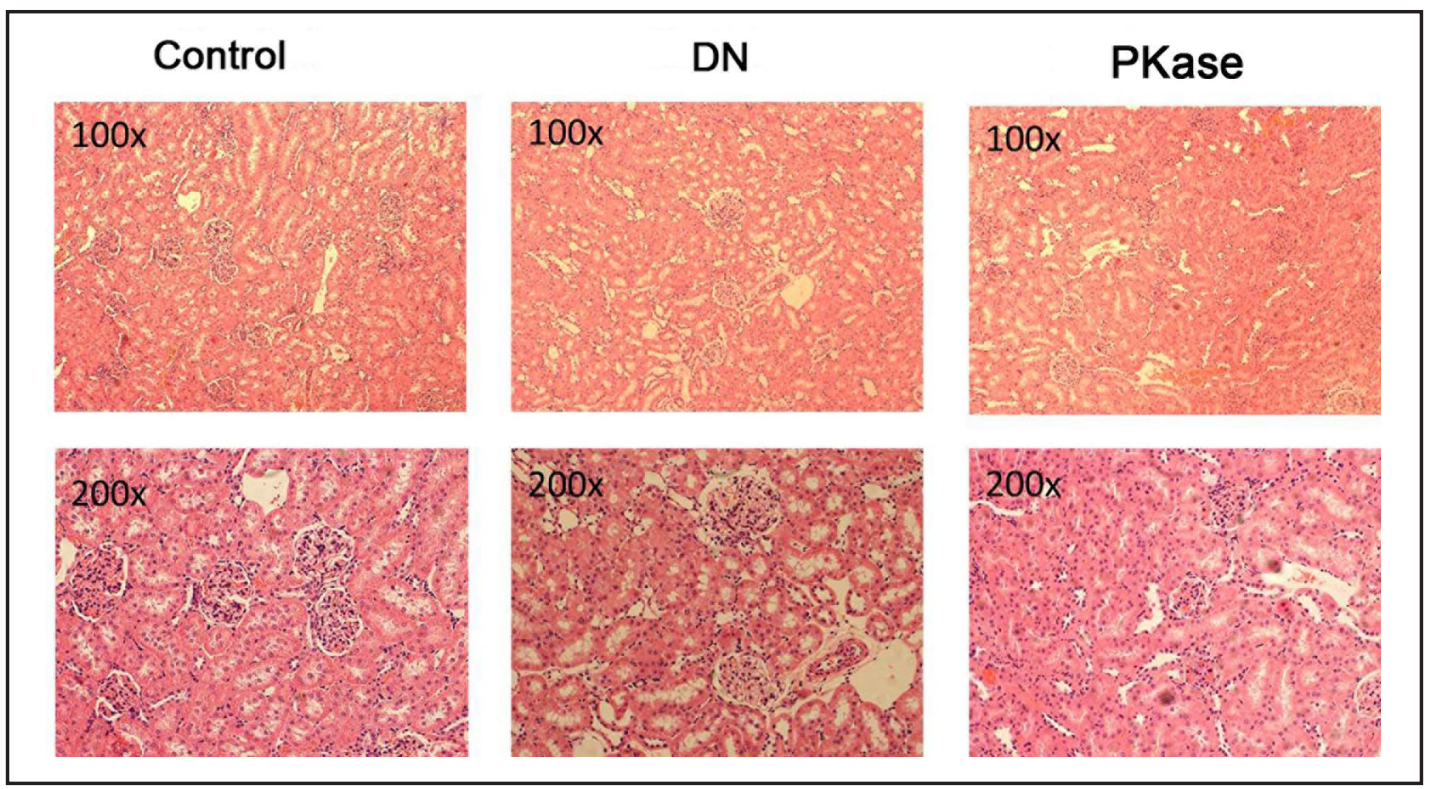

Fig. 1. Hematoxylin and Eosin staining in the control, DN and PKase groups. Renal tissues in the control group exhibited normal histological structure; renal tissues in the DN group exhibited mesenteria matrix hyperplasia and glomerular basement thickening; renal tissues in the PKase group exhibited alleviative pathological changes. DN, diabetic nephropathy; PKase, pancreatic kininogenase.

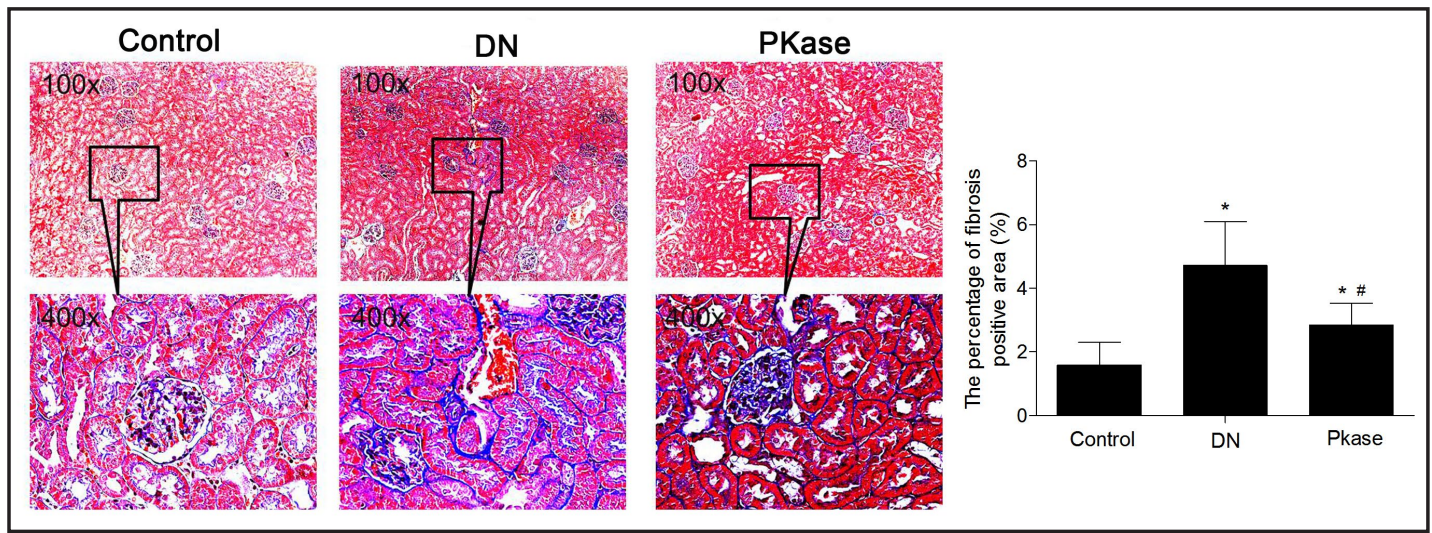

Fig. 2. Masson's trichrome staining in control, DN and PKase groups. Renal tissues in the control group exhibited normal histological structure; renal tissues in the DN group exhibited moderate tubulointerstitial fibrosis; renal tissues in the PKase group exhibited less deposition of extracellular matrix. The graph shows the densitometric quantification of the percentages of fibrosis positive area (\%). ${ }^{*} P<0.05$ versus control group, ${ }^{\#} P<0.05$ versus DN group. DN, diabetic nephropathy; PKase, pancreatic kininogenase.

with PKase for 4 weeks, these pathological changes were obviously alleviated in the rats of PKase group compared with the rats of DN group (Fig. 1). In addition, Masson's trichrome staining showed that renal tissues in the DN group exhibited moderate tubulointerstitial fibrosis compared with control group $(P<0.05)$, while the fibrosis was reduced after treatment with PKase $(P<0.05$, Fig. 2).

Effect of PKase on the levels of miR-433, TGF- $\beta 1$, and Azin1in renal tissues of DN rats Compared with the control group, the mRNA and protein levels of TGF- $\beta 1$ were elevated 


\section{Kidney Blood Pressure Research}

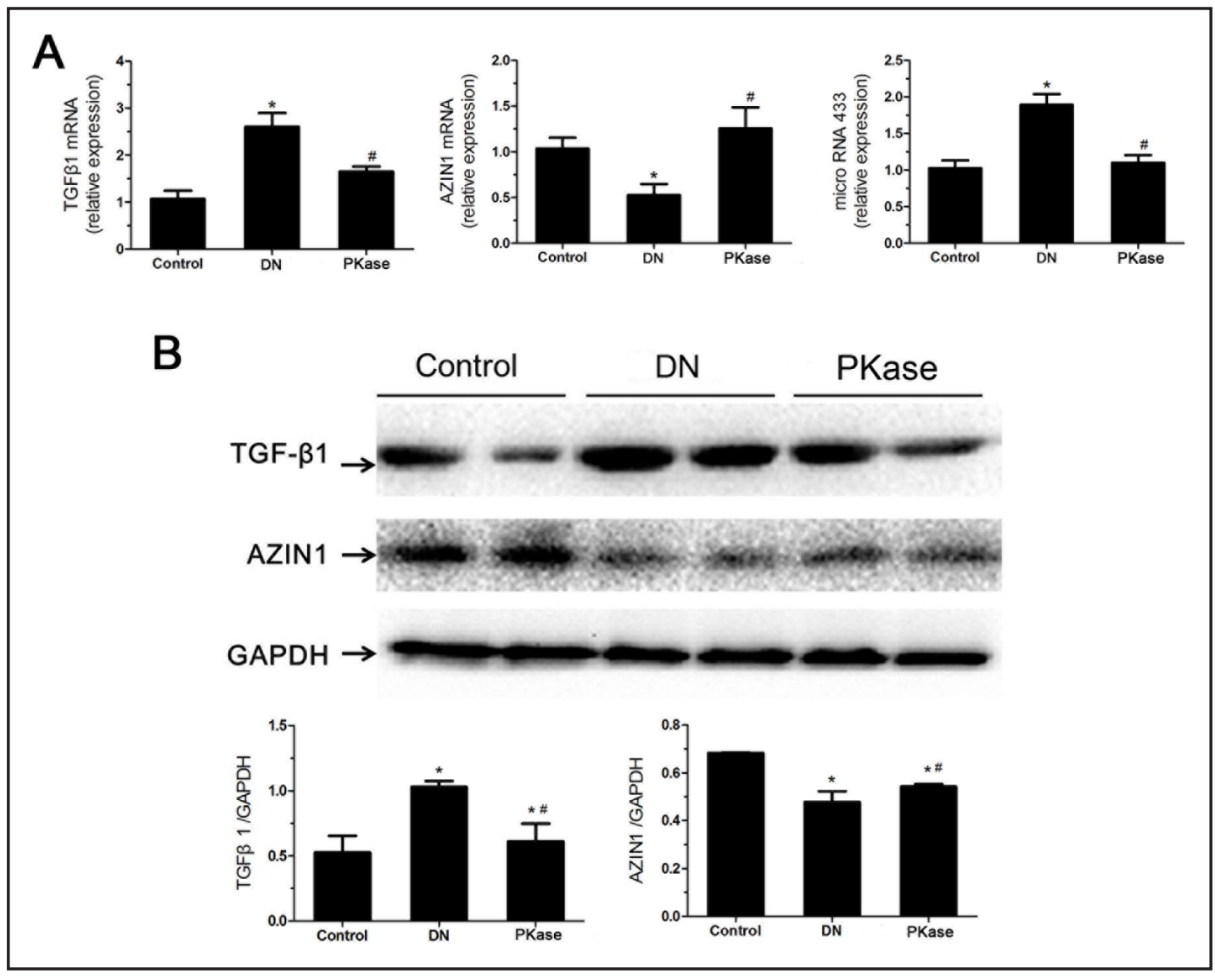

Fig. 3. The expression of miR-433, TGF- $\beta 1$, and Azin 1 in the control, DN and PKase groups. A, qRT-PCR analysis showed that the mRNA levels of miR-433 and TGF- $\beta 1$ were increased in the DN group compared with the control group, while decreased in the PKase group compared with the DN group. The mRNA levels of Azin1 had an opposite change trend with miR-433 and TGF- $\beta 1$; B, Western blotting analysis showed that the protein expressions of TGF- $\beta 1$ and Azin 1 had a similar change trend compared with the mRNA levels of TGF- $\beta 1$ and Azin1. ${ }^{*} P<0.05$ versus control group, ${ }^{\#} P<0.05$ versus DN group. DN, diabetic nephropathy; PKase, pancreatic kininogenase; TGF- $\beta 1$, transforming growth factor- $\beta 1$; Azin 1 , antizyme inhibitor 1.

$(P<0.05)$ in the renal tissues of DN group, while which were decreased $(P<0.05)$ after treatment with PKase (Fig. 3A, B). In addition, the mRNA levels of miR-433 had the similar change trend $(P<0.05)$ with TGF- $\beta 1$ (Fig. 3A). Conversely, the mRNA and protein levels of Azin1 were lower $(P<0.05)$ in the renal tissues of DN group than that of control group, while Azin 1 expression increased $(P<0.05)$ in the PKase group compared with the DN group (Figure 3A, B).

\section{Discussion}

In this study, we successfully established DN rats induced by STZ. It had been reported that DN rats exhibited increased blood glucose concentration, urinary protein content and urine output, as well as renal fibrosis [20]. Hyperglycemia had been considered as the initiating factor of the DN, which could increase renal blood flow, stimulate glomerular mesangial cell hypertrophy and renal hypertrophy, thereby resulting in renal function 


\section{Kidney \\ Blood Pressure Research}

impairment [21]. Then, lowering blood glucose concentration might reduce the incidence of DN [21]. Previous study had shown that PKase could promote the release of kinins, which was similar with the role of kallikrein [22]. Our results showed that PKase significantly inhibited the urinary weight, urinary protein content and blood glucose concentration in DN rats. Similarly, overexpression of human tissue kallikrein could attenuate STZ-induced renal diabetic phenotypes, including urinary albumin excretion, urinary osmolarity and histological changes [23]. In addition, Bodin et al. [24] also demonstrated that the lack of tissue kallikrein increased the albuminuria content in STZ-induced Type 1 diabetes mice compared with the control mice. These results suggested that PKase might be play an inhibiting role in the development of DN.

Previous study had demonstrated that tissue kallikrein alleviated salt-induced renal fibrosis through enhancing nitric oxide bioavailability, inhibiting the oxidative stress and down-regulating the expression of TGF- $\beta 1$ [25]. Consistently, we also found that PKase obviously relieved renal fibrosis in DN rats according to HE and Masson's trichrome staining. In some renal diseases, TGF- $\beta 1$ was associated with matrix synthesis and degradation [26, 27]. Consistent with a previous study [28], we also demonstrated that STZ could induce the increased mRNA and protein levels of TGF- $\beta 1$ in renal tissues. However, after treatment with PKase, the expression of TGF- $\beta 1$ was reduced, suggesting that PKase might relieve renal fibrosis in DN rats through inhibiting the expression of TGF- $\beta 1$.

Recent study had demonstrated that TGF- $\beta 1$ could be regulated by several miRNAs such as miR-21, miR-29, miR-192, miR-377 and miR-433 [16, 29-32]. MiRNAs had also been considered as indispensable factors for the development of DN [33]. In this study, we further found that after treatment with PKase, the mRNA level of miR-433 was reduced, while Azin1 expression was increased in the renal tissues of DN rats. Inverse expression of miR-433 and Azin1 were also found in human gastric carcinoma [34, 35]. Azin1 was a key enzyme in polyamine biosynthesis [36], while the lack of polyamine could promote the activation of TGF$\beta 1$ signaling $[37,38]$. In addition, increased Azin1 expression could inhibit the expression of $\alpha$-smooth muscle actin ( $\alpha$-SMA) and collagen I in cirrhotic livers [39], while the increased polyamine could inhibit the expression of $\alpha$-SMA induced by TGF- $\beta 1$ [40]. Collectively, these results indicated that after treatment with PKase, TGF- $\beta 1$-induced renal fibrosis might be inhibited by regulating the miR-433 level and Azin1 expression in STZ-induced DN rats.

However, our study have some limitations. First, a small number of rats are applied in this study. Second, the experimental design of the establishment of DN rats is not fully precise. We did not measure the pre and postprandial blood glucose during the establishment of DN rats, which should be improved in the future study.

\section{Conclusion}

In summary, our study found that PKase might inhibit the development of DN by reducing urinary weight, urinary protein content and blood glucose concentration in DN rats. In addition, PKase also relieved renal fibrosis in DN rats through inhibiting the expression of TGF- $\beta 1$, which might be associated with the miR-433 level and Azin1 expressions. All these results prompted that PKase might be a potential drug for the treatment of DN patients, while the further clinical application to the patients with DN and the therapeutic effect evaluation of PKase are necessary.

\section{Disclosure Statement}

All authors declare that they have no conflict of interests to state. 


\section{Kidney \\ Blood Pressure Research}

\section{Acknowledgement}

Zhu/Zhang/Cheng/Ren/Tang: Sun2Effect of PKase on STZ induced-DN rats

Our work was supported by Doctoral Fund of The First Affiliated Hospital of Harbin Medical University (2015B015).

\section{References}

1 Mauer SM, Steffes MW, Ellis EN, Sutherland D, Brown DM, Goetz FC: Structural-functional relationships in diabetic nephropathy. J Clin Invest 1984;74:1143.

2 Ziyadeh FN, Goldfarb S: The renal tubulointerstitium in diabetes mellitus. Kidney Int 1991;39:464-475.

3 Declèves A-E, Sharma K: New pharmacological treatments for improving renal outcomes in diabetes. Nat Rev Nephrol 2010;6:371-380.

4 Barnett A: Prevention of loss of renal function over time in patients with diabetic nephropathy. Am J Med 2006;119:S40-S47.

5 Dronavalli S, Duka I, Bakris GL: The pathogenesis of diabetic nephropathy. Nat Clin Pract Endocrinol Metab 2008;4:444-452.

6 Wei J-X, Wang Y: Clinical Observation of Pancreatic Kininogenase Enteric Coated Tablets and Benazepril in Treatment of 40 Patients with Diabetic Nephropathy. J Modern Clin Med 2012;6:008.

7 Wang M-J, Liu F, Zhais S-D: Treating Diabetic Nephropathy with Pancreatic Kallikrein: A Systematic Review. China Pharmacy 2008;17:020.

8 Bhoola K, Figueroa C, Worthy K: Bioregulation of kinins: kallikreins, kininogens, and kininases. Pharmacol Rev 1992;44:1-80.

9 Riad A, Zhuo JL, Schultheiss HP, Tschöpe C: The role of the renal kallikrein-kinin system in diabetic nephropathy. Curr Opin Nephrol Hypertens 2007;16:22.

10 Hoffman BB, Sharma K, Ziyadeh FN: Potential role of TGF-beta in diabetic nephropathy. Miner Electrolyte Metab 1997;24:190-196.

11 Feger M, Alesutan I, Castor T, Mia S, Musculus K, Voelkl J, Lang F: Inhibitory Effect of NH4Cl Treatment on Renal Tgfß1 Signaling Following Unilateral Ureteral Obstruction. Cell Physiol Biochem 2015;37:955-964.

12 Pan B, Liu G, Jiang Z, Zheng D: Regulation of Renal Fibrosis by Macrophage Polarization. Cell Physiol Biochem 2015;35:1062-1069.

13 Yamamoto T, Nakamura T, Noble NA, Ruoslahti E, Border WA: Expression of transforming growth factor beta is elevated in human and experimental diabetic nephropathy. Proc Natl Acad Sci 1993;90:1814-1818.

14 Sharma K, Jin Y, Guo J, Ziyadeh FN: Neutralization of TGF- $\beta$ by anti-TGF- $\beta$ antibody attenuates kidney hypertrophy and the enhanced extracellular matrix gene expression in STZ-induced diabetic mice. Diabetes 1996;45:522-530.

15 Ziyadeh FN: Mediators of diabetic renal disease: the case for TGF- $\beta$ as the major mediator. J Am Soc Nephrol 2004;15:S55-S57.

16 Li R, Chung AC, Dong Y, Yang W, Zhong X, Lan HY: The microRNA miR-433 promotes renal fibrosis by amplifying the TGF- $\beta$ /Smad3-Azin1 pathway. Kidney Int 2013;84:1129-1144.

17 Yin X, Zhang Y, Wu H, Zhu X, Zheng X, Jiang S, Zhuo H, Shen J, Li L, Qiu J: Protective effects of Astragalus saponin I on early stage of diabetic nephropathy in rats. J Pharmacol Sci 2004;95:256-266.

18 Li X, Cui X, Sun X, Li X, Zhu Q, Li W: Mangiferin prevents diabetic nephropathy progression in streptozotocin-induced diabetic rats. Phytother Res 2010;24:893-899.

19 Rocha-Martins M, Njaine B, Silveira MS: Avoiding pitfalls of internal controls: validation of reference genes for analysis by qRT-PCR and Western blot throughout rat retinal development. PLoS One 2012;7:e43028.

20 Mogensen C, Christensen C, Vittinghus E: The stages in diabetic renal disease: with emphasis on the stage of incipient diabetic nephropathy. Diabetes 1983;32:64-78.

21 Schena FP, Gesualdo L: Pathogenetic mechanisms of diabetic nephropathy. J Am Soc Nephrol 2005;16:S30-S33. 


\section{Kidney \\ Blood Pressure Research}

22 Schachter M: Kallikreins (kininogenases)--a group of serine proteases with bioregulatory actions. Pharmacol Rev 1979;31:1-17.

23 Yuan G, Deng J, Wang T, Zhao C, Xu X, Wang P, Voltz JW, Edin ML, Xiao X, Chao L: Tissue kallikrein reverses insulin resistance and attenuates nephropathy in diabetic rats by activation of phosphatidylinositol 3-kinase/protein kinase B and adenosine 5'-monophosphate-activated protein kinase signaling pathways. Endocrinology 2007;148:2016-2026.

24 Bodin S, Chollet C, Goncalves-Mendes N, Gardes J, Pean F, Heudes D, Bruneval P, Marre M, Alhenc-Gelas F, Bouby N: Kallikrein protects against microalbuminuria in experimental type I diabetes. Kidney Int 2009;76:395-403.

25 Zhang JJ, Bledsoe G, Kato K, Chao L, Chao J: Tissue kallikrein attenuates salt-induced renal fibrosis by inhibition of oxidative stress. Kidney Int 2004;66:722-732.

26 Mizuno S, Matsumoto K, Kurosawa T, Mizuno-Horikawa Y, Nakamura T: Reciprocal balance of hepatocyte growth factor and transforming growth factor- $\beta 1$ in renal fibrosis in mice. Kidney Int 2000;57:937-948.

27 Peters H, Noble NA, Border WA: Transforming growth factor-[beta] in human glomerular injury. Curr Opin Nephrol Hypertens 1997;6:389-393.

28 Russo LM, del Re E, Brown D, Lin HY: Evidence for a role of transforming growth factor (TGF)- $\beta 1$ in the induction of postglomerular albuminuria in diabetic nephropathy amelioration by soluble TGF- $\beta$ type II receptor. Diabetes 2007;56:380-388.

29 Zhong X, Chung AC, Chen H-Y, Meng X-M, Lan HY: Smad3-mediated upregulation of miR-21 promotes renal fibrosis. J Am Soc Nephrol 2011;22:1668-1681.

30 Qin W, Chung AC, Huang XR, Meng X-M, Hui DS, Yu C-M, Sung JJ, Lan HY: TGF- $\beta /$ Smad3 signaling promotes renal fibrosis by inhibiting miR-29. J Am Soc Nephrol 2011;22:1462-1474.

31 Chung AC, Huang XR, Meng X, Lan HY: miR-192 mediates TGF- $\beta$ /Smad3-driven renal fibrosis. J Am Soc Nephrol 2010;21:1317-1325.

32 Wang Q, Wang Y, Minto AW, Wang J, Shi Q, Li X, Quigg RJ: MicroRNA-377 is up-regulated and can lead to increased fibronectin production in diabetic nephropathy. FASEB J 2008;22:4126-4135.

33 Chandrasekaran K, Karolina DS, Sepramaniam S, Armugam A, Wintour EM, Bertram JF, Jeyaseelan K: Role of microRNAs in kidney homeostasis and disease. Kidney Int 2012;81:617-627.

34 Luo H, Zhang H, Zhang Z, Zhang X, Ning B, Guo J, Nie N, Liu B, Wu X: Down-regulated miR-9 and miR-433 in human gastric carcinoma. J Exp Clin Cancer Res 2009;28:1-9.

35 Jung MH, Kim SC, Jeon GA, Kim SH, Kim Y, Choi KS, Park SI, Joe MK, Kimm K: Identification of differentially expressed genes in normal and tumor human gastric tissue. Genomics 2000;69:281-286.

36 Kahana C: Regulation of cellular polyamine levels and cellular proliferation by antizyme and antizyme inhibitor. Essays Biochem 2009;46:47-62.

37 Liu L, Santora R, Rao JN, Guo X, Zou T, Zhang HM, Turner DJ, Wang J-Y: Activation of TGF- $\beta$-Smad signaling pathway following polyamine depletion in intestinal epithelial cells. Am J Physiol Cell Physiol 2003;285:G1056-G1067.

38 Rao JN, Li L, Bass BL, Wang J-Y: Expression of the TGF- $\beta$ receptor gene and sensitivity to growth inhibition following polyamine depletion. Am J Physiol Cell Physiol 2000;279:C1034-C1044.

39 Paris AJ, Snapir Z, Christopherson CD, Kwok SY, Lee UE, Ghiassi-Nejad Z, Kocabayoglu P, Sninsky JJ, Llovet JM, Kahana C: A polymorphism that delays fibrosis in hepatitis C promotes alternative splicing of AZIN1, reducing fibrogenesis. Hepatology 2011;54:2198-2207.

40 Compagnone A, Bandino A, Meli F, Bravoco V, Cravanzola C, Parola M, Colombatto S: Polyamines modulate epithelial-to-mesenchymal transition. Amino acids 2012;42:783-789. 